Supporting Information For

\title{
Atomic Resolution Analyses of Isocoumarin Derivatives for Inhibition of Lysyl-tRNA Synthetase
}

\author{
Jintong Zhou, ${ }^{\dagger}$ Li Zheng, ${ }^{\dagger}$ Zhoufei Hei,${ }^{\dagger}$ Wei Li,,${ }^{\ddagger}$ Jing Wang,,${ }^{\dagger} \S$ Biao Yu,,${ }^{\dagger,}$ Pengfei Fang ${ }^{\dagger, \S^{*}}$ \\ 'State Key Laboratory of Bioorganic and Natural Products Chemistry, Center for Excellence in Molecular \\ Synthesis, Shanghai Institute of Organic Chemistry, University of Chinese Academy of Sciences, Chinese \\ Academy of Sciences, 345 Lingling Road, Shanghai 200032, China \\ tDepartment of Medicinal Chemistry, School of Pharmacy, China Pharmaceutical University, 639 Longmian \\ Avenue, Nanjing, Jiangsu 211198, China \\ ${ }^{\S}$ School of Chemistry and Material Sciences, Hangzhou Institute for Advanced Study, University of Chinese \\ Academy of Sciences, 1 Sub-lane Xiangshan, Hangzhou 310024, China \\ *Email: fangpengfei@ sioc.ac.cn.
}

This file includes:

Supplementary methods;

Supplementary figures 1-11. 


\section{Method of Compound Synthesis}

Chemical shifts are given in ppm (d), coupling constantans are given in Hz. Signal splitting patterns are described as singlet (s), doublet (d), triplet (t), quartet (q), multiplet (m), broad (br), or a combination thereof.

Compound 4: (E)-2-(cyclohexylmethylene)-5,7-dimethoxy-2,3-dihydro-1H-inden-1-one

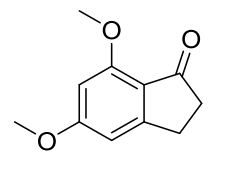

1

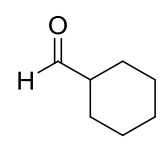

2

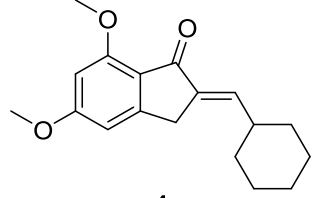

To a solution of $1(500 \mathrm{mg}, 2.60 \mathrm{mmol})$ in THF $(10 \mathrm{~mL})$ was added $\mathrm{CH}_{3} \mathrm{ONa}(239 \mathrm{mg}, 4.42 \mathrm{mmol})$ under argon at room temperature (RT). The solution was stirred for $30 \mathrm{~min}$ before 2 (321 mg, $2.86 \mathrm{mmol}$ ) in THF $(10 \mathrm{~mL})$ solution was added dropwise. The resulting mixture was stirred at RT for $20 \mathrm{~h}$ under argon. After completion, the reaction was quenched with water $(20 \mathrm{~mL})$. The aqueous layer was extracted with DCM (3 $\times 20 \mathrm{~mL}$ ). The combined organic layer was washed with brine, dried over $\mathrm{Na}_{2} \mathrm{SO}_{4}$, and concentrated under reduced pressure. The residue was purified by flash chromatography (PE/EA 3:1) leading to an off-white solid 4 (518 mg, 70\% yield). ${ }^{1} \mathrm{H}$ NMR $\left(500 \mathrm{MHz}, \mathrm{CDCl}_{3}\right) \delta 6.58(\mathrm{dd}, J=9.7,2.0 \mathrm{~Hz}, 1 \mathrm{H}), 6.50(\mathrm{~s}, 1 \mathrm{H}), 6.32$ (s, 1H), 3.92 (s, 3H), 3.88 (s, 3H), $3.58(\mathrm{~s}, 2 \mathrm{H}), 2.29$ (d, $J=10.1 \mathrm{~Hz}, 1 \mathrm{H}), 1.77(\mathrm{~d}, J=9.4 \mathrm{~Hz}, 2 \mathrm{H}), 1.71$ (d, $J=12.2 \mathrm{~Hz}, 3 \mathrm{H}), 1.35-1.23(\mathrm{~m}, 5 \mathrm{H}) .{ }^{13} \mathrm{C} \mathrm{NMR}\left(126 \mathrm{MHz}, \mathrm{CDCl}_{3}\right) \delta 190.3,166.6,160.1,154.3,140.0,134.8$, $101.5,97.4,55.8,55.7,39.0,32.0,30.0,25.9,25.6$.

Compound 5: (E)-5,7-dimethoxy-2-((3-methylcyclohexyl)methylene)-2,3-dihydro-1H-inden-1-one

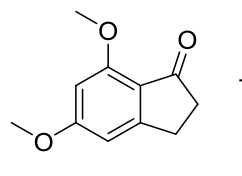<smiles>CC1CCCC(C=O)C1</smiles>

3

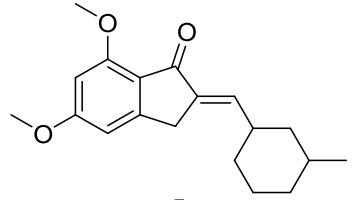

5

To a solution of $1(1.36 \mathrm{~g}, 7.08 \mathrm{mmol})$ in THF $(20 \mathrm{~mL})$ was added $\mathrm{CH}_{3} \mathrm{ONa}(590 \mathrm{mg}, 10.9 \mathrm{mmol})$ under argon at RT. The solution was stirred for $30 \mathrm{~min}$ before $\mathbf{3}$ ( $800 \mathrm{mg}, 6.44 \mathrm{mmol}$ ) in THF ( $20 \mathrm{~mL}$ ) solution was added dropwise. The resulting mixture was stirred at RT for $20 \mathrm{~h}$ under argon. After completion, the reaction was quenched with water $(20 \mathrm{~mL})$. The aqueous layer was extracted with DCM $(3 \times 20 \mathrm{~mL})$. The combined organic layer was washed with brine, dried over $\mathrm{Na}_{2} \mathrm{SO}_{4}$, and concentrated under reduced pressure. The residue was purified by flash chromatography (PE/EA 3:1) leading to colorless oil 5 (710 mg, 37\% yield). ${ }^{1} \mathrm{H}$ NMR $\left(500 \mathrm{MHz}, \mathrm{CDCl}_{3}\right) \delta 6.60(\mathrm{dd}, J=9.7,2.0 \mathrm{~Hz}, 1 \mathrm{H}), 6.52(\mathrm{~s}, 1 \mathrm{H}), 6.34(\mathrm{~s}, 1 \mathrm{H}), 3.94(\mathrm{~s}, 3 \mathrm{H}), 3.90$ (s, $3 \mathrm{H}), 3.60(\mathrm{~s}, 2 \mathrm{H}), 2.31(\mathrm{~d}, J=10.1 \mathrm{~Hz}, 1 \mathrm{H}), 1.75-1.62(\mathrm{~m}, 2 \mathrm{H}), 1.53-1.25(\mathrm{~m}, 4 \mathrm{H}), 0.96-0.79(\mathrm{~m}, 5 \mathrm{H}), 0.62$ $(\mathrm{m}, 1 \mathrm{H})$. 


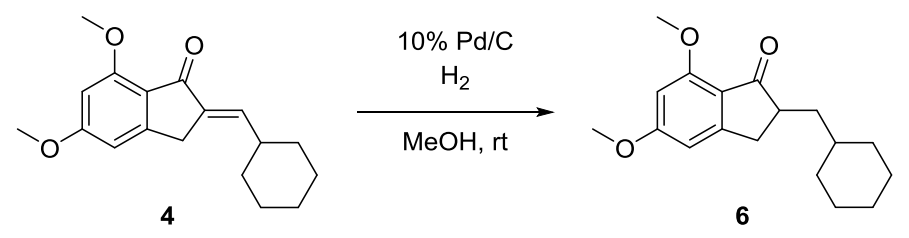

To a solution of 4 (200 mg, $0.70 \mathrm{mmol})$ in $\mathrm{MeOH}(10 \mathrm{~mL})$ was added palladium $10 \%$ on activated carbon (10 mg, $0.5 \%$ eq.). The mixture was stirred under hydrogen atmosphere for $1 \mathrm{~h}$. The mixture was filtered and concentrated to give the product $6\left(202 \mathrm{mg}, 100 \%\right.$ yield) as a colorless solid. ${ }^{1} \mathrm{H}$ NMR $\left(500 \mathrm{MHz}^{\mathrm{CDCl}}{ }_{3}\right) \delta$ $6.44(\mathrm{~s}, 1 \mathrm{H}), 6.28(\mathrm{~s}, 1 \mathrm{H}), 3.89(\mathrm{~s}, 3 \mathrm{H}), 3.86(\mathrm{~s}, 3 \mathrm{H}), 3.18(\mathrm{dd}, J=17.9,8.5 \mathrm{~Hz}, 1 \mathrm{H}), 2.67$ (ddd, $J=10.3,9.2$, $3.9 \mathrm{~Hz}, 2 \mathrm{H}), 1.89-1.76(\mathrm{~m}, 2 \mathrm{H}), 1.76-1.61(\mathrm{~m}, 4 \mathrm{H}), 1.50-1.38$ (m, 1H), 1.29-1.10 (m, 4H), 1.040 .87 (m, 2H). ${ }^{13} \mathrm{C} \mathrm{NMR}\left(126 \mathrm{MHz}, \mathrm{CDCl}_{3}\right) \delta 205.4,166.8,159.4,158.8,119.0,101.5,97.4,55.7,55.7,45.6,39.7$, $36.1,34.2,33.5,32.5,26.6,26.4,26.3$.

Compound 7: 5,7-dimethoxy-2-((3-methylcyclohexyl)methyl)-2,3-dihydro-1H-inden-1-one

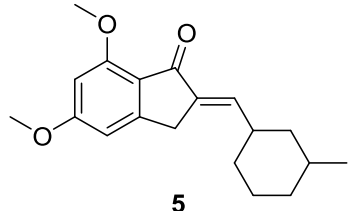

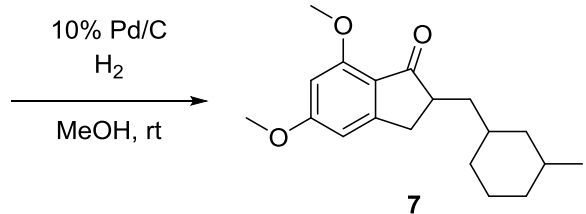

7

To a solution of 5 (600 mg, $2.0 \mathrm{mmol})$ in $\mathrm{MeOH}(20 \mathrm{~mL})$ was added palladium $10 \%$ on activated carbon (15 $\mathrm{mg}, 0.2 \%$ eq.). The mixture was stirred under hydrogen atmosphere for $2 \mathrm{~h}$. The mixture was filtered and concentrated to give the product 7 (596 mg, 98.7\% yield) as a light yellow oil. ${ }^{1} \mathrm{H} \mathrm{NMR}\left(400 \mathrm{MHz}^{\mathrm{CDCl}} \mathrm{CD}_{3}\right)$ $\delta 6.45(\mathrm{~s}, 1 \mathrm{H}), 6.29(\mathrm{~d}, J=1.2 \mathrm{~Hz}, 1 \mathrm{H}), 3.90(\mathrm{~s}, 3 \mathrm{H}), 3.87(\mathrm{~s}, 3 \mathrm{H}), 3.20(\mathrm{dd}, J=18.1,8.6 \mathrm{~Hz}, 1 \mathrm{H}), 2.68(\mathrm{dt}$, $J=13.2,3.5 \mathrm{~Hz}, 2 \mathrm{H}), 1.88-1.73(\mathrm{~m}, 3 \mathrm{H}), 1.70-1.62(\mathrm{~m}, 2 \mathrm{H}), 1.52-1.24(\mathrm{~m}, 4 \mathrm{H}), 0.95-0.79(\mathrm{~m}, 5 \mathrm{H}), 0.62$ (dd, $J=24.1,12.2 \mathrm{~Hz}, 1 \mathrm{H})$.

Compound 8: 2-(cyclohexylmethyl)-4,6-dimethoxy-1H-inden-3-yl 2,2,2-trifluoroacetate

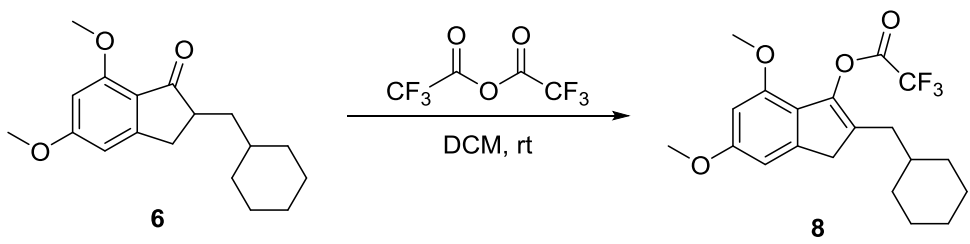

To a solution of $6(100 \mathrm{mg}, 0.347 \mathrm{mmol})$ in dichloromethane $(0.5 \mathrm{~mL})$ was added $2.0 \mathrm{~mL}$ of trifluoroacetic anhydride, and the reaction was stirred for $1.5 \mathrm{~h}$ at RT. The excess anhydride was removed under vacuum. The residue was purified by flash chromatography (PE/EA 20:1) to give 8 (95 mg, 71\% yield) as a white solid. ${ }^{1} \mathrm{H}$ NMR $\left(500 \mathrm{MHz}, \mathrm{CDCl}_{3}\right) \delta 6.61(\mathrm{~d}, J=0.9 \mathrm{~Hz}, 1 \mathrm{H}), 6.36(\mathrm{~d}, J=1.7 \mathrm{~Hz}, 1 \mathrm{H}), 3.80(\mathrm{~s}, 3 \mathrm{H}), 3.75(\mathrm{~s}$, 3H), 3.31 (s, 2H), 2.22 (d, $J=7.2 \mathrm{~Hz}, 2 \mathrm{H}), 1.69$ (d, $J=11.8 \mathrm{~Hz}, 4 \mathrm{H}), 1.63$ (d, $J=10.5 \mathrm{~Hz}, 1 \mathrm{H}), 1.53-1.43$ 
$(\mathrm{m}, 1 \mathrm{H}), 1.18(\mathrm{dd}, J=19.7,10.6 \mathrm{~Hz}, 3 \mathrm{H}), 0.92(\mathrm{q}, J=11.5 \mathrm{~Hz}, 2 \mathrm{H}) .{ }^{13} \mathrm{C} \mathrm{NMR}\left(126 \mathrm{MHz}, \mathrm{CDCl}_{3}\right) \delta 159.8$, $155.7,155.4,152.3,143.3,142.0,128.3,118.9,102.3,97.4,55.6,55.3,37.9,37.7,33.8,33.2,26.3,26.2$.

\section{Compound 9: 4,6-dimethoxy-2-((3-methylcyclohexyl)methyl)-1H-inden-3-yl 2,2,2-trifluoroacetate}
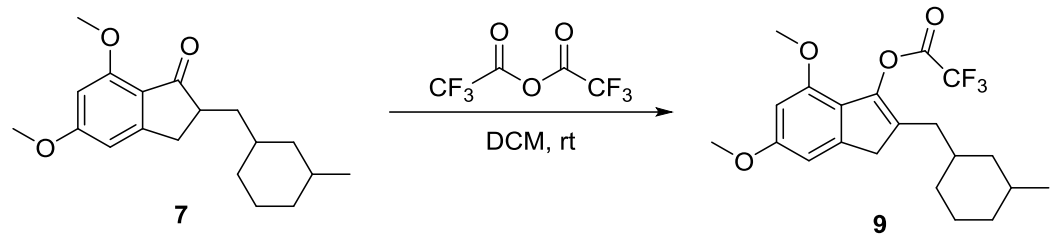

To a solution of $7(300 \mathrm{mg}, 0.990 \mathrm{mmol})$ in dichloromethane $(1.0 \mathrm{~mL})$ was added $6.0 \mathrm{~mL}$ of trifluoroacetic anhydride, and the reaction was stirred for $2 \mathrm{~h}$ at RT. The excess anhydride was removed under vacuum. The residue was purified by flash chromatography (PE/EA 20:1) to give 9 (230 mg, 58.3\% yield) as a light yellow oil. ${ }^{1} \mathrm{H}$ NMR (400 MHz, $\left.\mathrm{CDCl}_{3}\right) \delta 6.61(\mathrm{~d}, J=1.3 \mathrm{~Hz}, 1 \mathrm{H}), 6.37(\mathrm{t}, J=4.0 \mathrm{~Hz}, 1 \mathrm{H}), 3.80(\mathrm{~s}, 3 \mathrm{H}), 3.75(\mathrm{~s}$, $3 \mathrm{H}), 3.31(\mathrm{~s}, 2 \mathrm{H}), 2.21(\mathrm{~d}, J=7.1 \mathrm{~Hz}, 2 \mathrm{H}), 1.78-1.60(\mathrm{~m}, 4 \mathrm{H}), 1.54-1.45(\mathrm{~m}, 1 \mathrm{H}), 1.39-1.19(\mathrm{~m}, 2 \mathrm{H}), 0.92-$ $0.78(\mathrm{~m}, 5 \mathrm{H}), 0.57(\mathrm{dd}, J=24.4,11.9 \mathrm{~Hz}, 1 \mathrm{H})$.

\section{Compound 10: 3-(cyclohexylmethyl)-6,8-dimethoxy-1H-isochromen-1-one}

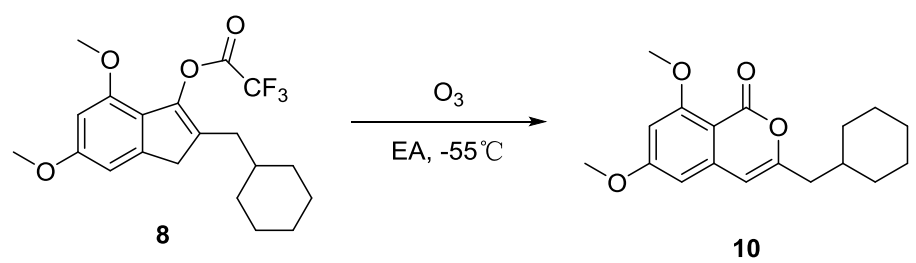

The enol trifluoroacetate 8 was ozonolyzed at 220 V, 7.5 psi oxygen, and a flow rate of 0.5 SLPM (standard liters per minute). Ozone was bubbled into $8(82 \mathrm{mg}, 0.21 \mathrm{mmol})$ in $5.0 \mathrm{~mL}$ of ethyl acetate at $-55{ }^{\circ} \mathrm{C}$ for 15 min. The reaction was stopped before the color of solution was obviously blue. The system was flushed with nitrogen and then $0.5 \mathrm{~mL}$ of dimethyl sulfide was added. The resulting mixture was then stirred overnight at RT. Upon completion, the solution was then washed with saturated aqueous $\mathrm{NaHCO}_{3}(2 \times 5 \mathrm{~mL})$ and brine $(5 \mathrm{~mL})$. After concentration in vacuum, the residue was purified by flash chromatography (PE/EA 5:1) leading to 10 (40 mg, 62\% yield) as a colorless oil. ${ }^{1} \mathrm{H}$ NMR $\left(500 \mathrm{MHz}, \mathrm{CDCl}_{3}\right) \delta 6.40(\mathrm{~d}, J=2.2 \mathrm{~Hz}, 1 \mathrm{H})$, $6.30(\mathrm{~d}, J=2.2 \mathrm{~Hz}, 1 \mathrm{H}), 6.04(\mathrm{~s}, 1 \mathrm{H}), 3.93(\mathrm{~s}, 3 \mathrm{H}), 3.87(\mathrm{~s}, 3 \mathrm{H}), 2.29(\mathrm{~d}, J=7.1 \mathrm{~Hz}, 2 \mathrm{H}), 1.78(\mathrm{~m}, 1 \mathrm{H}), 1.74-$ $1.58(\mathrm{~m}, 5 \mathrm{H}), 1.28-1.16(\mathrm{~m}, 2 \mathrm{H}), 1.16-1.06(\mathrm{~m}, 1 \mathrm{H}), 0.94(\mathrm{dt}, J=23.4,6.1 \mathrm{~Hz}, 2 \mathrm{H}) .{ }^{13} \mathrm{C} \mathrm{NMR}(126 \mathrm{MHz}$, $\mathrm{CDCl} 3) \delta 165.3,163.2,159.7,157.9,142.3,104.1,103.0,99.4,98.2,56.2,55.6,41.3,35.6,33.0,26.3,26.0$. 

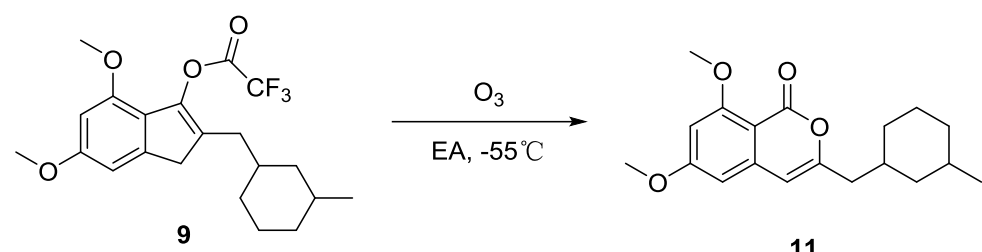

11

The enol trifluoroacetate 9 was ozonolyzed at 220 V, 7.5 psi oxygen, and a flow rate of 0.5 SLPM. Ozone was bubbled into $9(150 \mathrm{mg}, 0.39 \mathrm{mmol})$ in $10 \mathrm{~mL}$ of ethyl acetate at $-55^{\circ} \mathrm{C}$ for $15 \mathrm{~min}$. The reaction was stopped before the color of solution was obviously blue. The system was flushed with nitrogen and then 1 $\mathrm{mL}$ of dimethyl sulfide was added. The resulting mixture was then stirred overnight at RT. Upon completion, the solution was then washed with saturated aqueous $\mathrm{NaHCO}_{3}(2 \times 10 \mathrm{~mL})$ and saturated brine $(10 \mathrm{~mL})$. After concentration in vacuum, the residue was purified by flash chromatography (PE/EA 5:1) leading to 11 (95 mg, 80\% yield) as a light yellow oil. ${ }^{1} \mathrm{H}$ NMR $\left(500 \mathrm{MHz}, \mathrm{CDCl}_{3}\right) \delta 6.41(\mathrm{~d}, J=2.2 \mathrm{~Hz}, 1 \mathrm{H}), 6.31(\mathrm{~d}, J$ $=2.2 \mathrm{~Hz}, 1 \mathrm{H}), 6.06(\mathrm{~s}, 1 \mathrm{H}), 3.95(\mathrm{~s}, 3 \mathrm{H}), 3.88(\mathrm{~s}, 3 \mathrm{H}), 2.30(\mathrm{qd}, J=14.1,7.1 \mathrm{~Hz}, 2 \mathrm{H}), 1.81(\mathrm{~m}, 1 \mathrm{H}), 1.74-$ $1.61(\mathrm{~m}, 4 \mathrm{H}), 1.35(\mathrm{~m}, 1 \mathrm{H}), 1.30-1.21(\mathrm{~m}, 1 \mathrm{H}), 0.91-0.77(\mathrm{~m}, 5 \mathrm{H}), 0.59(\mathrm{q}, J=11.9 \mathrm{~Hz}, 1 \mathrm{H}) .{ }^{13} \mathrm{C} \mathrm{NMR}(126$ $\left.\mathrm{MHz}, \mathrm{CDCl}_{3}\right) \delta 165.3,163.3,159.8,157.9,142.3,104.1,103.0,99.4,98.2,56.3,55.6,41.7,41.4,35.7,35.0$, $32.7,32.4,26.0,22.8$.

\section{Compound 12: 3-(cyclohexylmethyl)-6,8-dimethoxyisochroman-1-one}

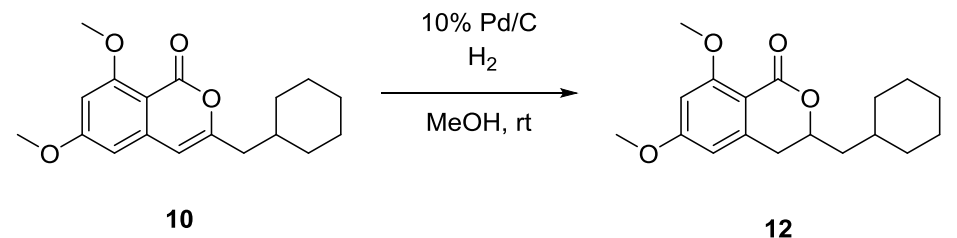

To a solution of $10(25 \mathrm{mg}, 0.083 \mathrm{mmol})$ in $\mathrm{MeOH}(2 \mathrm{~mL})$ was added palladium $10 \%$ on activated carbon $(50 \mathrm{mg}, 20 \%$ eq.). The mixture was stirred under hydrogen atmosphere for 1 day. The mixture was filtered and concentrated to give the product 12 (18 mg, 71\% yield) as a colorless oil. ${ }^{1} \mathrm{H}$ NMR (500 MHz, $\left.\mathrm{CDCl}_{3}\right) \delta$ 6.39 (s, 1H), 6.29 (s, 1H), 4.45 (t, $J=9.5 \mathrm{~Hz}, 1 \mathrm{H}), 3.90$ (s, 3H), 3.85 (s, 3H), $2.80(\mathrm{dt}, J=15.7,14.8 \mathrm{~Hz}, 2 \mathrm{H})$, $1.83-1.73(\mathrm{~m}, 2 \mathrm{H}), 1.66(\mathrm{t}, J=13.5 \mathrm{~Hz}, 5 \mathrm{H}), 1.45-1.36(\mathrm{~m}, 1 \mathrm{H}), 1.23(\mathrm{~d}, J=9.3 \mathrm{~Hz}, 2 \mathrm{H}), 1.18-1.08(\mathrm{~m}, 1 \mathrm{H})$, $1.00-0.83(\mathrm{~m}, 2 \mathrm{H}) .{ }^{13} \mathrm{C} \mathrm{NMR}\left(126 \mathrm{MHz}, \mathrm{CDCl}_{3}\right) \delta 164.2,163.0,162.8,144.0,107.2,103.8,97.7,74.9,56.1$, $55.5,42.4,35.5,33.8,33.2,32.8,26.5,26.2,26.0$.

Compound 13: 6,8-dimethoxy-3-((3-methylcyclohexyl)methyl)isochroman-1-one

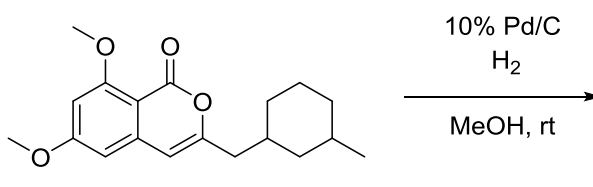

11

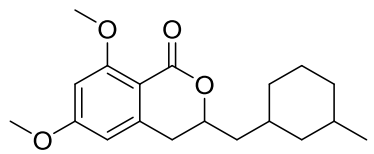

13 
To a solution of 11 (40 mg, $0.127 \mathrm{mmol})$ in $\mathrm{MeOH}(3 \mathrm{~mL})$ was added palladium $10 \%$ on activated carbon (40 mg, 10\% eq.). The mixture was stirred under hydrogen atmosphere overnight. The mixture was filtered and concentrated to give the product 13 (32 mg, 79.2\% yield) as a colorless oil. ${ }^{1} \mathrm{H}$ NMR (500 MHz, $\mathrm{CDCl}_{3}$ ) $\delta 6.39(\mathrm{~s}, 1 \mathrm{H}), 6.29(\mathrm{~s}, 1 \mathrm{H}), 4.47(\mathrm{~s}, 1 \mathrm{H}), 3.90(\mathrm{~s}, 3 \mathrm{H}), 3.84(\mathrm{~s}, 3 \mathrm{H}), 2.90-2.70(\mathrm{~m}, 2 \mathrm{H}), 1.68(\mathrm{~m}, 5 \mathrm{H}), 1.31$ (m, 4H), 0.92-0.77 (m, 5H), 0.66-0.47 (m, 1H). ${ }^{13} \mathrm{C}$ NMR (126 MHz, $\left.\mathrm{CDCl}_{3}\right) \delta$ 164.3, 163.0, 162.8, 144.0, $107.1,103.8,97.7,74.8,56.1,55.5,42.6,41.6,35.5,35.1,33.4,32.5,32.4,26.1,22.8$.

\section{Compound 14: 3-(cyclohexylmethyl)-8-hydroxy-6-methoxyisochroman-1-one and}

Compound 16: 3-(cyclohexylmethyl)-6,8-dihydroxyisochroman-1-one

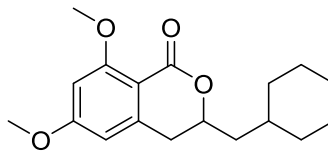

12

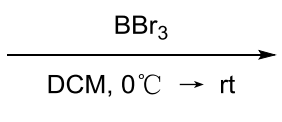

14

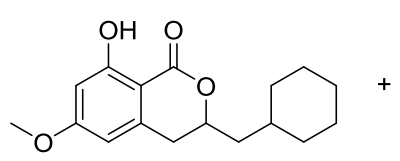

14

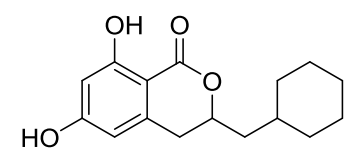

16

To a solution of $12(18 \mathrm{mg}, 0.062 \mathrm{mmol})$ in dry dichloromethane $(2 \mathrm{~mL})$ was added dropwise 2.2 eq. of $\mathrm{BBr}_{3}\left(1 \mathrm{M}\right.$ solution in dichloromethane) at $0{ }^{\circ} \mathrm{C}$. The reaction was warmed to $\mathrm{RT}$ and stirred overnight under argon. The mixture was quenched with water and extracted with ethyl acetate $(3 \times 5 \mathrm{~mL})$. The organic phase was dried over $\mathrm{Na}_{2} \mathrm{SO}_{4}$. After concentration under vacuum, the crude product was purified by flash chromatography (PE/Acetone 5:1) leading to $\mathbf{1 4}$ (1 $\mathrm{mg}, 6 \%$ yield) as a white solid and $\mathbf{1 6}$ (8 $\mathrm{mg}, 49 \%$ yield) as a white solid. 14: ${ }^{1} \mathrm{H}$ NMR $\left(500 \mathrm{MHz}, \mathrm{CDCl}_{3}\right) \delta 11.25(\mathrm{~s}, 1 \mathrm{H}), 6.36(\mathrm{~d}, J=2.3 \mathrm{~Hz}, 1 \mathrm{H}), 6.24(\mathrm{~d}, J=2.3$ $\mathrm{Hz}, 1 \mathrm{H}), 4.67-4.58(\mathrm{~m}, 1 \mathrm{H}), 3.82(\mathrm{~s}, 3 \mathrm{H}), 2.87-2.82(\mathrm{~m}, 2 \mathrm{H}), 1.81$ (s, 1H), 1.71 (d, $J=6.3 \mathrm{~Hz}, 2 \mathrm{H}), 1.69$ (s, 3H), 1.50-1.44 (m, 1H), 1.25 (s, 3H), 1.03-0.85 (m, 3H). 16: ${ }^{1} \mathrm{H}$ NMR (500 MHz, acetone-D6) $\delta 11.29$ (s, 1H), 9.56-9.29 (m, 1H), 6.32-6.28 (m, 1H), 6.26 (d, $J=2.1 \mathrm{~Hz}, 1 \mathrm{H}), 4.75-4.62(\mathrm{~m}, 1 \mathrm{H}), 2.95$ (dd, $J=16.5$, $3.3 \mathrm{~Hz}, 1 \mathrm{H}), 2.87-2.80(\mathrm{~m}, 1 \mathrm{H}), 1.90-1.81(\mathrm{~m}, 1 \mathrm{H}), 1.80-1.72(\mathrm{~m}, 2 \mathrm{H}), 1.72-1.65(\mathrm{~m}, 3 \mathrm{H}), 1.54(\mathrm{~m}, 1 \mathrm{H})$, $1.35-1.23(\mathrm{~m}, 3 \mathrm{H}), 1.23-1.16(\mathrm{~m}, 1 \mathrm{H}), 1.07-0.87(\mathrm{~m}, 2 \mathrm{H}) .{ }^{13} \mathrm{C}$ NMR (126 MHz, acetone-D6) $\delta 169.8,164.3$, 164.2, 142.4, 106.6, 101.0, 76.8, 42.3, 33.5, 33.1, 32.6, 26.3, 26.0, 25.9. HRMS calculated for $\mathrm{C}_{16} \mathrm{H}_{21} \mathrm{O}_{4}[\mathrm{M}$ $+\mathrm{H}]^{+}$277.1437, observed 277.1434.

\section{Compound 15: 8-hydroxy-6-methoxy-3-((3-methylcyclohexyl)methyl)isochroman-1-one and}

Compound 17: 6,8-dihydroxy-3-((3-methylcyclohexyl)methyl)isochroman-1-one<smiles>COc1cc2c(c(OC)c1)C(=O)OC(CC1CCCC(C)C1)C2</smiles>

13
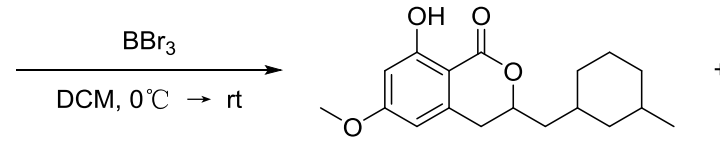

15

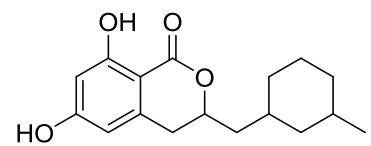

17 
To a solution of $\mathbf{1 3}(20 \mathrm{mg}, 0.066 \mathrm{mmol})$ in dry dichloromethane $(2 \mathrm{~mL})$ was added dropwise 2.2 eq. of $\mathrm{BBr}_{3}$ (1 M solution in dichloromethane) at $0{ }^{\circ} \mathrm{C}$. The reaction was warmed to RT and stirred under argon. The mixture was quenched with water and extracted with ethyl acetate $(3 \times 5 \mathrm{~mL})$. The organic phase was dried over $\mathrm{Na}_{2} \mathrm{SO}_{4}$. After concentration under vacuum, the crude product was purified by flash chromatography (PE/Acetone 5:1) leading to $\mathbf{1 5}$ (1 mg, 6\% yield) as a light yellow oil and $\mathbf{1 7}$ (9 mg, $49 \%$ yield) as a light yellow oil. 15: ${ }^{1} \mathrm{H}$ NMR $\left(500 \mathrm{MHz}, \mathrm{CDCl}_{3}\right) \delta 11.50-11.41(\mathrm{~m}, 1 \mathrm{H}), 6.48-6.46(\mathrm{~m}, 1 \mathrm{H}), 6.46-6.44(\mathrm{~m}, 1 \mathrm{H})$, 4.69-4.57 (m, 1H), 3.93 (s, 3H), 3.24-3.17 (m, 1H), 2.81-2.71 (m, 1H), 1.88-1.76 (m, 2H), 1.75-1.64 (m, 3H), $1.28(\mathrm{~s}, 4 \mathrm{H}), 0.94-0.81(\mathrm{~m}, 5 \mathrm{H}), 0.68-0.53(\mathrm{~m}, 1 \mathrm{H}) .17:{ }^{1} \mathrm{H}$ NMR (500 MHz, acetone-D6) $\delta 11.30$ (s, $1 \mathrm{H}), 9.67-9.38(\mathrm{~m}, 1 \mathrm{H}), 6.31(\mathrm{~d}, J=0.8 \mathrm{~Hz}, 1 \mathrm{H}), 6.26(\mathrm{~d}, J=2.2 \mathrm{~Hz}, 1 \mathrm{H}), 4.75-4.66(\mathrm{~m}, 1 \mathrm{H}), 3.01-2.87(\mathrm{~m}$, $2 \mathrm{H}), 1.90-1.82(\mathrm{~m}, 1 \mathrm{H}), 1.79-1.64(\mathrm{~m}, 4 \mathrm{H}), 1.47-1.25(\mathrm{~m}, 3 \mathrm{H}), 1.22-1.18(\mathrm{~m}, 1 \mathrm{H}), 0.95-0.81(\mathrm{~m}, 5 \mathrm{H}), 0.69-$ $0.56(\mathrm{~m}, 1 \mathrm{H}) .{ }^{13} \mathrm{C}$ NMR $(126 \mathrm{MHz}$, acetone-D6) $\delta 169.8,164.3,164.2,142.4,110.0,106.6,101.0,76.8,42.4$, 41.4, 35.0, 33.4, 33.1, 32.4, 32.1, 25.9, 22.3. LRMS for $\mathrm{C}_{17} \mathrm{H}_{21} \mathrm{O}_{4}[\mathrm{M}-\mathrm{H}]^{-} 289.10$.

\section{Compound 18: 3-(cyclohexylmethyl)-8-hydroxy-6-methoxy-1H-isochromen-1-one and}

Compound 20: 3-(cyclohexylmethyl)-6,8-dihydroxy-1H-isochromen-1-one

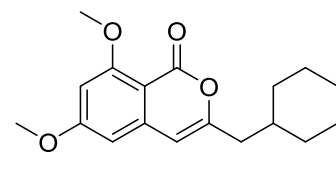

10
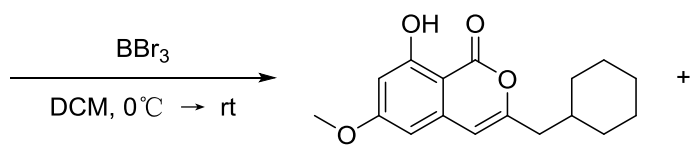

18

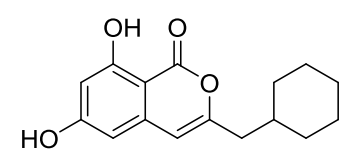

20

To a solution of $10(20 \mathrm{mg}, 0.069 \mathrm{mmol})$ in dry dichloromethane $(2 \mathrm{~mL})$ was added dropwise 2.2 eq. of $\mathrm{BBr}_{3}$ (1 M solution in dichloromethane) at $0{ }^{\circ} \mathrm{C}$. The reaction was warmed to RT and stirred under argon. The mixture was quenched with water and extracted with ethyl acetate $(3 \times 5 \mathrm{~mL})$. The organic phase was dried over $\mathrm{Na}_{2} \mathrm{SO}_{4}$. After concentration under vacuum, the crude product was purified by flash chromatography (PE/Acetone 5:1) leading to $\mathbf{1 8}$ (9 $\mathrm{mg}, 47 \%$ yield) as a white solid and $\mathbf{2 0}$ (9 $\mathrm{mg}, 49 \%$ yield) as a light yellow solid. 18: ${ }^{1} \mathrm{H}$ NMR (400 MHz, $\left.\mathrm{CDCl}_{3}\right) \delta 11.13(\mathrm{~s}, 1 \mathrm{H}), 6.45(\mathrm{~d}, J=2.3 \mathrm{~Hz}, 1 \mathrm{H}), 6.30(\mathrm{~d}, J=2.3 \mathrm{~Hz}, 1 \mathrm{H})$, $6.15(\mathrm{~s}, 1 \mathrm{H}), 3.86(\mathrm{~s}, 3 \mathrm{H}), 2.35$ (d, $J=6.9 \mathrm{~Hz}, 2 \mathrm{H}), 1.85-1.59$ (m, 6H), 1.33-1.09 (m, 3H), 1.04-0.89 (m, 2H). 20: ${ }^{1} \mathrm{H}$ NMR (400 MHz, Acetone-D6) $\delta 11.17$ (s, 1H), 9.67 (s, 1H), 6.42 (d, $\left.J=2.1 \mathrm{~Hz}, 1 \mathrm{H}\right), 6.40$ (s, $1 \mathrm{H}), 6.38(\mathrm{~d}, J=2.1 \mathrm{~Hz}, 1 \mathrm{H}), 2.39$ (d, $J=6.7 \mathrm{~Hz}, 2 \mathrm{H}), 1.82-1.63(\mathrm{~m}, 6 \mathrm{H}), 1.24(\mathrm{~m}, 3 \mathrm{H}), 1.09-0.94(\mathrm{~m}, 2 \mathrm{H})$. ${ }^{13} \mathrm{C}$ NMR (126 MHz, acetone-D6) $\delta$ 166.3, 165.4, 163.7, 156.6, 140.0, 104.8, 102.4, 101.3, 98.8, 40.6, 35.8, 32.6, 26.1, 25.8. LRMS for $\mathrm{C}_{16} \mathrm{H}_{17} \mathrm{O}_{4}[\mathrm{M}-\mathrm{H}]^{-} 273.20$.

Compound 19: 8-hydroxy-6-methoxy-3-((3-methylcyclohexyl)methyl)-1H-isochromen-1-one and Compound 21: 6,8-dihydroxy-3-((3-methylcyclohexyl)methyl)-1H-isochromen-1-one 


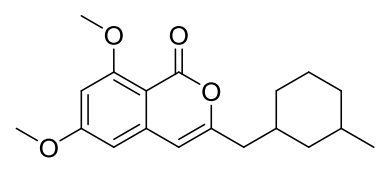

11

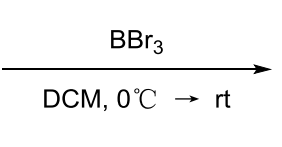$$
\mathrm{O}^{\prime}
$$$$
\text { , }
$$

19

19

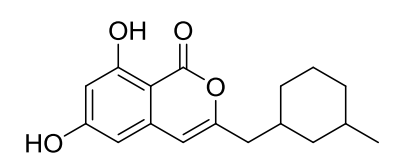

21

To a solution of 11 (20 mg, $0.066 \mathrm{mmol})$ in dry dichloromethane ( $2 \mathrm{~mL})$ was added dropwise 2.2 eq. of $\mathrm{BBr}_{3}$ (1 M solution in dichloromethane) at $0{ }^{\circ} \mathrm{C}$. The reaction was warmed to RT and stirred under argon. The mixture was quenched with water and extracted with ethyl acetate $(3 \times 5 \mathrm{~mL})$. The organic phase was dried over $\mathrm{Na}_{2} \mathrm{SO}_{4}$. After concentration under vacuum, the crude product was purified by flash chromatography (PE/Acetone 5:1) leading to $\mathbf{1 9}$ (1 mg, 5\% yield) as a white solid and $\mathbf{2 1}$ (17 $\mathrm{mg}, 93 \%$ yield) as a light yellow solid. 19: ${ }^{1} \mathrm{H}$ NMR (400 MHz, $\left.\mathrm{CDCl}_{3}\right) \delta 11.13(\mathrm{~s}, 1 \mathrm{H}), 6.46(\mathrm{~d}, J=2.3 \mathrm{~Hz}, 1 \mathrm{H}), 6.31(\mathrm{~d}, \mathrm{~J}=2.3 \mathrm{~Hz}, 1 \mathrm{H})$, $6.15(\mathrm{~s}, 1 \mathrm{H}), 3.86(\mathrm{~s}, 3 \mathrm{H}), 2.43-2.29(\mathrm{~m}, 2 \mathrm{H}), 1.77-1.63(\mathrm{~m}, 4 \mathrm{H}), 1.41-1.21(\mathrm{~m}, 3 \mathrm{H}), 0.93-0.79(\mathrm{~m}, 5 \mathrm{H})$, $0.61(\mathrm{~d}, J=12.3 \mathrm{~Hz}, 1 \mathrm{H}) .21:{ }^{1} \mathrm{H} \mathrm{NMR}(500 \mathrm{MHz}$, acetone) $\delta 11.17(\mathrm{~s}, 1 \mathrm{H}), 9.63(\mathrm{~s}, 1 \mathrm{H}), 6.43-6.36(\mathrm{~m}, 3 \mathrm{H})$, 2.45-2.34 (m, 2H), 1.84-1.62 (m, 5H), 1.45-1.26 (m, 2H), 0.98-0.78 (m, 5H), $0.66(\mathrm{q}, J=12.1 \mathrm{~Hz}, 1 \mathrm{H}) .{ }^{13} \mathrm{C}$ NMR (126 MHz, acetone-D6) $\delta$ 166.2, 165.4, 163.7, 156.6, 140.0, 110.0, 104.8, 102.4, 101.3, 41.5, 40.8, 35.9, 34.8, 32.4, 32.3, 25.8, 22.2. HRMS calculated for $\mathrm{C}_{17} \mathrm{H}_{19} \mathrm{O}_{4}[\mathrm{M}-\mathrm{H}]^{-}$287.1290, observed 287.1289.

Compound 22: (E)-5,7-dimethoxy-2-((3-methylcyclohexyl)methyl)-2,3-dihydro-1H-inden-1-one oxime
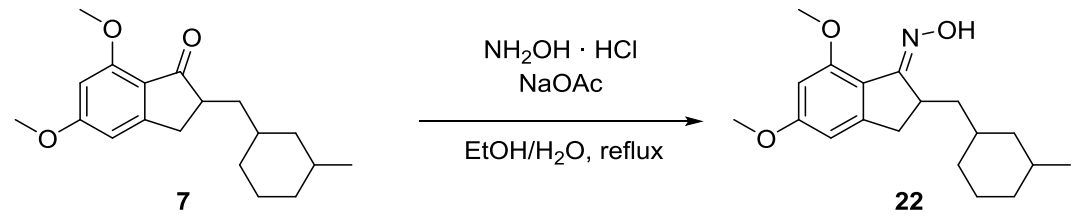

To a mixture of 7 (100 mg, $0.315 \mathrm{mmol})$ and hydroxylamine hydrochloride (46 mg, $0.66 \mathrm{mmol}) \mathrm{in} \mathrm{EtOH} / \mathrm{H}_{2} \mathrm{O}$ $(6.7 \mathrm{~mL} / 3.3 \mathrm{~mL})$ was added sodium acetate $(55 \mathrm{mg}, 0.66 \mathrm{mmol})$. After refluxing for $4 \mathrm{~h}$, the reaction mixture was poured into water and the product was isolated by filtration to give a white solid $\mathbf{2 2}$ (96 $\mathrm{mg}$, $92 \%$ yield). ${ }^{1} \mathrm{H}$ NMR $\left(400 \mathrm{MHz}, \mathrm{CDCl}_{3}\right) \delta 6.44(\mathrm{~d}, J=12.6 \mathrm{~Hz}, 1 \mathrm{H}), 6.35-6.28(\mathrm{~m}, 1 \mathrm{H}), 3.90(\mathrm{~s}, 3 \mathrm{H}), 3.85(\mathrm{~d}, J=13.8$ $\mathrm{Hz}, 3 \mathrm{H}), 3.60$ (s, 1H), 3.12 (m, 1H), 2.75-2.63 (m, 1H), 1.96 (m, 1H), 1.88-1.57 (m, 4H), 1.50-1.20 (m, 4H), $1.13(\mathrm{~m}, 1 \mathrm{H}), 0.86(\mathrm{~m}, 5 \mathrm{H}), 0.74-0.55(\mathrm{~m}, 1 \mathrm{H})$.

\section{Compound 23: 6,8-dihydroxy-3-((3-methylcyclohexyl)methyl)-3,4-dihydroisoquinolin-1(2H)-one}
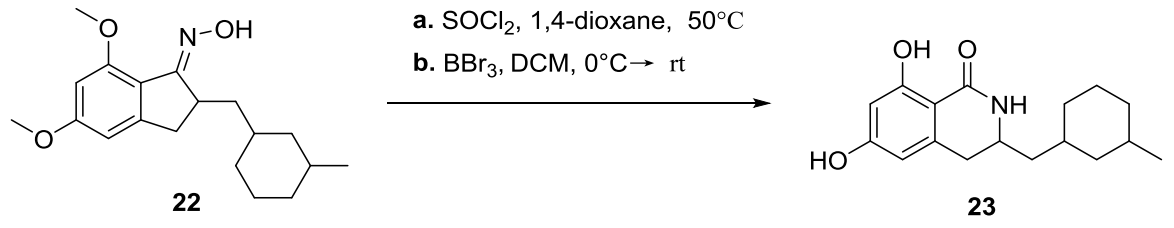

To the solution of $22(100 \mathrm{mg}, 0.315 \mathrm{mmol})$ in dry 1,4-dioxane $(3 \mathrm{~mL})$ was added dropwise $\mathrm{SOCl}_{2}(0.35 \mathrm{~mL}$, $5.0 \mathrm{mmol})$ in dry 1,4 -dioxane $(2 \mathrm{~mL})$ at $0{ }^{\circ} \mathrm{C}$. The reaction was heated to $70{ }^{\circ} \mathrm{C}$ for $4.5 \mathrm{~h}$. The mixture was 
quenched with water and extracted with ethyl acetate $(3 \times 5 \mathrm{~mL})$. The organic phase was dried over $\mathrm{Na}_{2} \mathrm{SO}_{4}$. After concentration under vacuum, the amide crude was used in the next step without further purification.

To a solution of the amide crude in dry dichloromethane $(5 \mathrm{~mL})$ was added dropwise 2.4 eq. of $\mathrm{BBr}_{3}(1 \mathrm{M}$ solution in dichloromethane) at $0{ }^{\circ} \mathrm{C}$. The reaction was warmed to RT and stirred overnight under argon. The mixture was quenched with water and extracted with ethyl acetate $(3 \times 10 \mathrm{~mL})$. The organic phase was dried over $\mathrm{Na}_{2} \mathrm{SO}_{4}$. After concentration under vacuum, the crude product was purified by flash chromatography (PE/EA 3:1) leading to $\mathbf{2 3}$ (1 mg, 5\% yield) as a yellow oil. ${ }^{1} \mathrm{H}$ NMR (500 MHz, $\left.\mathrm{CDCl}_{3}\right) \delta 6.25(\mathrm{~d}, J=2.0$ $\mathrm{Hz}, 1 \mathrm{H}), 6.17(\mathrm{~s}, 1 \mathrm{H}), 5.88-5.80(\mathrm{~m}, 1 \mathrm{H}), 5.74(\mathrm{~s}, 1 \mathrm{H}), 3.83-3.73(\mathrm{~m}, 1 \mathrm{H}), 2.85(\mathrm{~d}, J=15.6 \mathrm{~Hz}, 1 \mathrm{H}), 2.72-$ $2.65(\mathrm{~m}, 1 \mathrm{H}), 2.65(\mathrm{~s}, 1 \mathrm{H}), 1.79-1.60(\mathrm{~m}, 4 \mathrm{H}), 1.58-1.47(\mathrm{~m}, 2 \mathrm{H}), 1.40(\mathrm{~m}, 3 \mathrm{H}), 0.93-0.75(\mathrm{~m}, 5 \mathrm{H}), 0.65-$ $0.52(\mathrm{~m}, 1 \mathrm{H})$. LRMS for $\mathrm{C}_{17} \mathrm{H}_{24} \mathrm{NO}_{3}[\mathrm{M}+\mathrm{H}]^{+} 290.00$. 


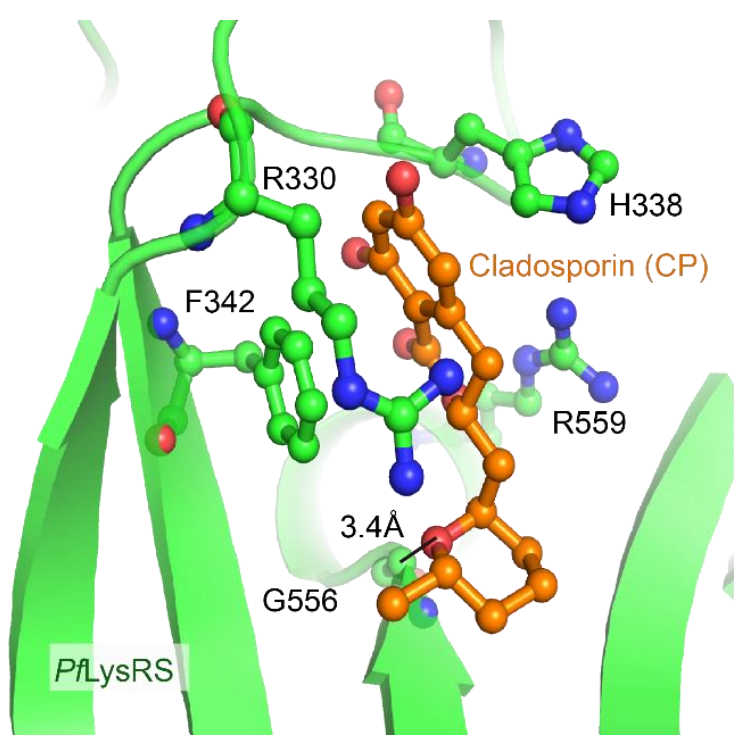

Figure S1. A zoom-in view of $\boldsymbol{P} f$ LysRS-Cladosporin complex structure in the active center. The Plasmodium falciparum lysyl-tRNA synthetase (PfLysRS) is shown as a green cartoon (PDB ID: 4YCV). The bound cladosporin molecule is shown as orange sticks. The interacting residues from the enzyme is shown as green sticks. 

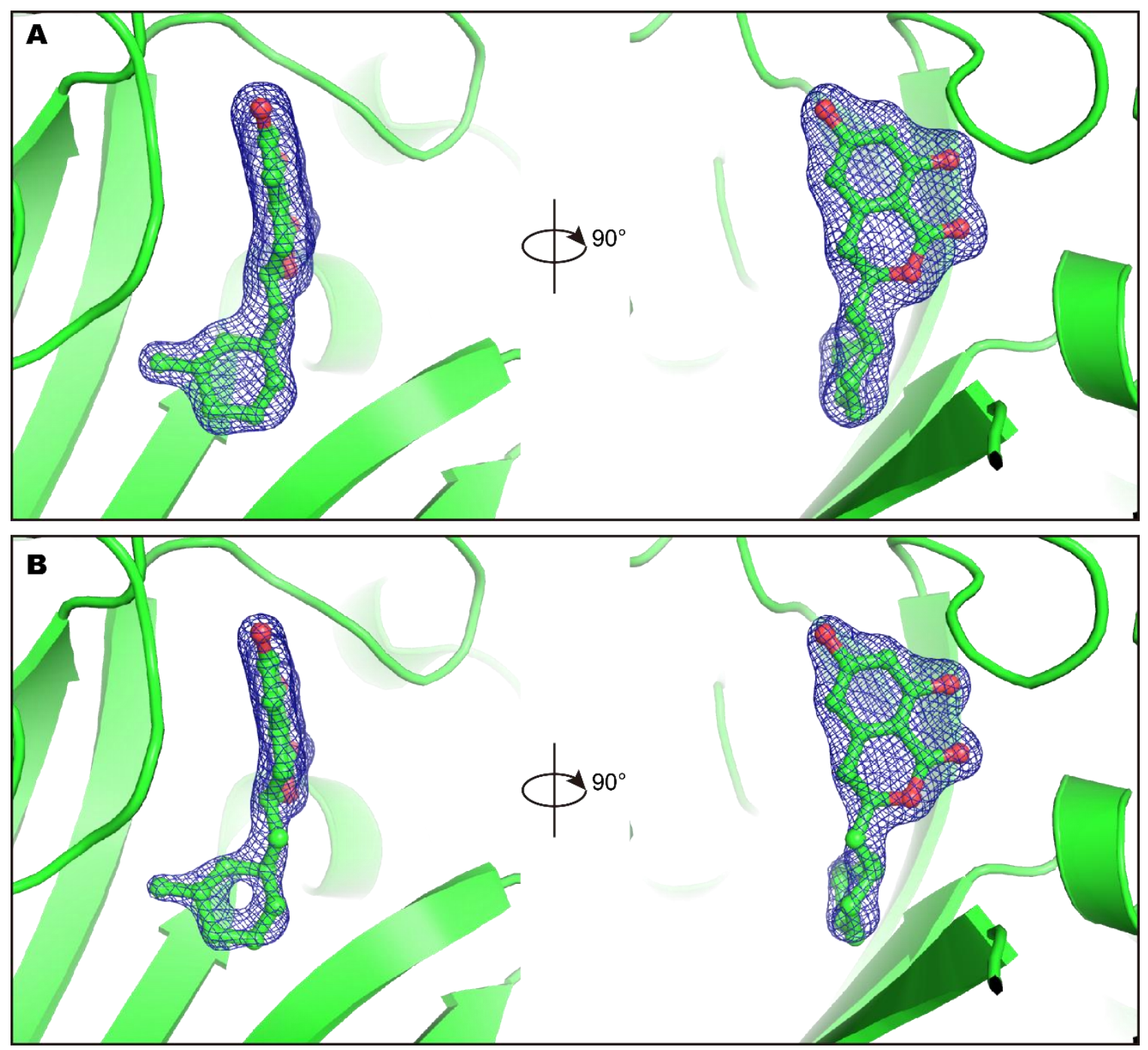

Figure S2. Electron density of compound 17 in the $P f$ LysRS-17 complex structure. (A) 2Fo-Fc maps are contoured at $\sigma=1.0$ level. (B) $2 \mathrm{Fo}-\mathrm{Fc}$ maps are contoured at $\sigma=2.0$ level. 


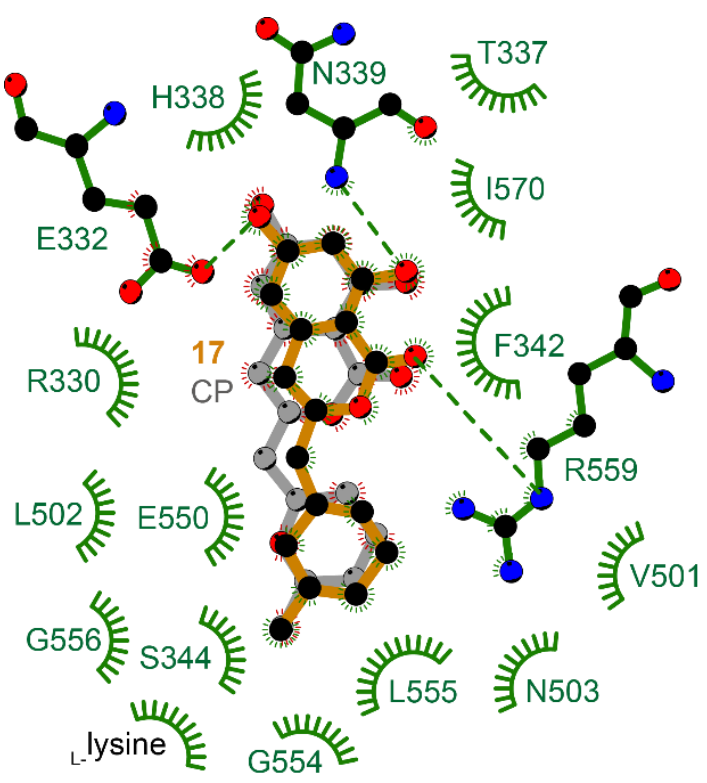

Figure S3. Two-dimensional presentation of compound 17 binding in PfLysRS. Hydrogen-bonding residues and chemicals are shown in stick representations. Hydrophobic interactions are shown in green radial patterns. All the interactions are conserved with cladosporin (CP, grey sticks). 

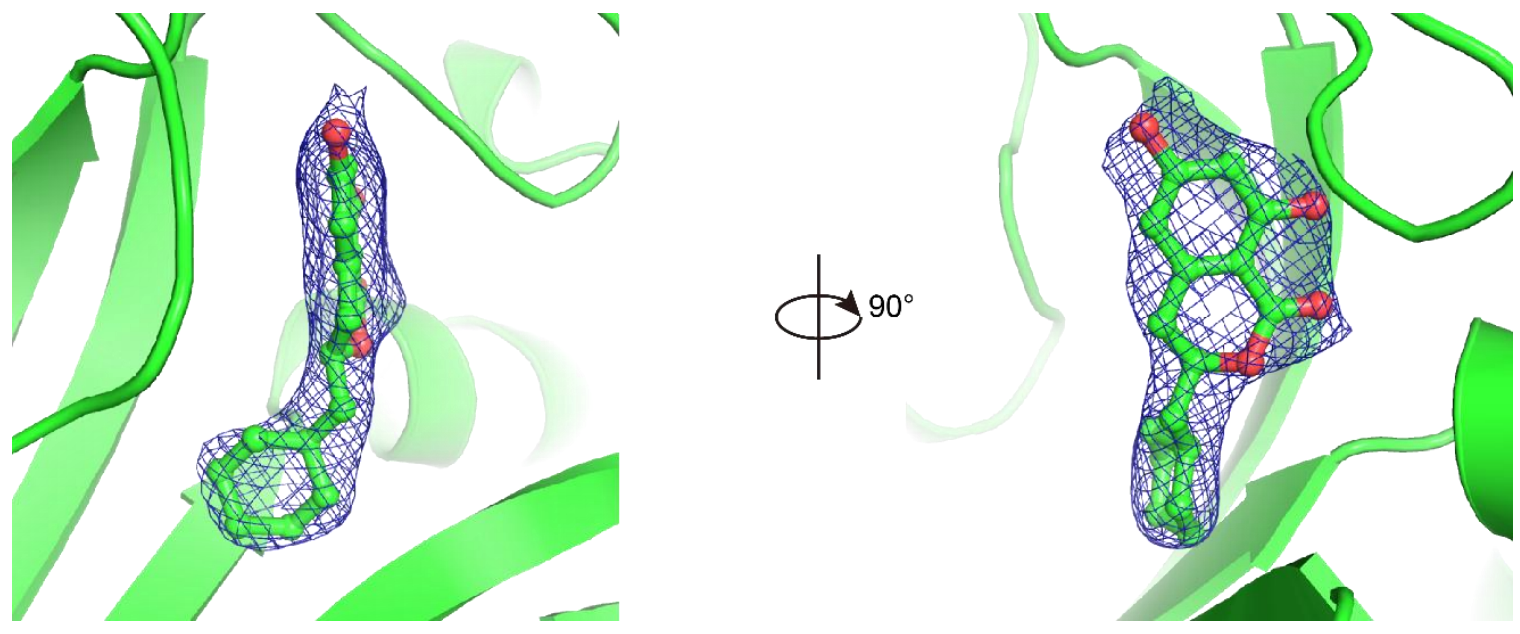

Figure S4. Electron density of compound 16 in the $P f$ LysRS-16 complex structure. $2 \mathrm{Fo}-\mathrm{Fc}$ maps are contoured at $\sigma=1.0$ level. 


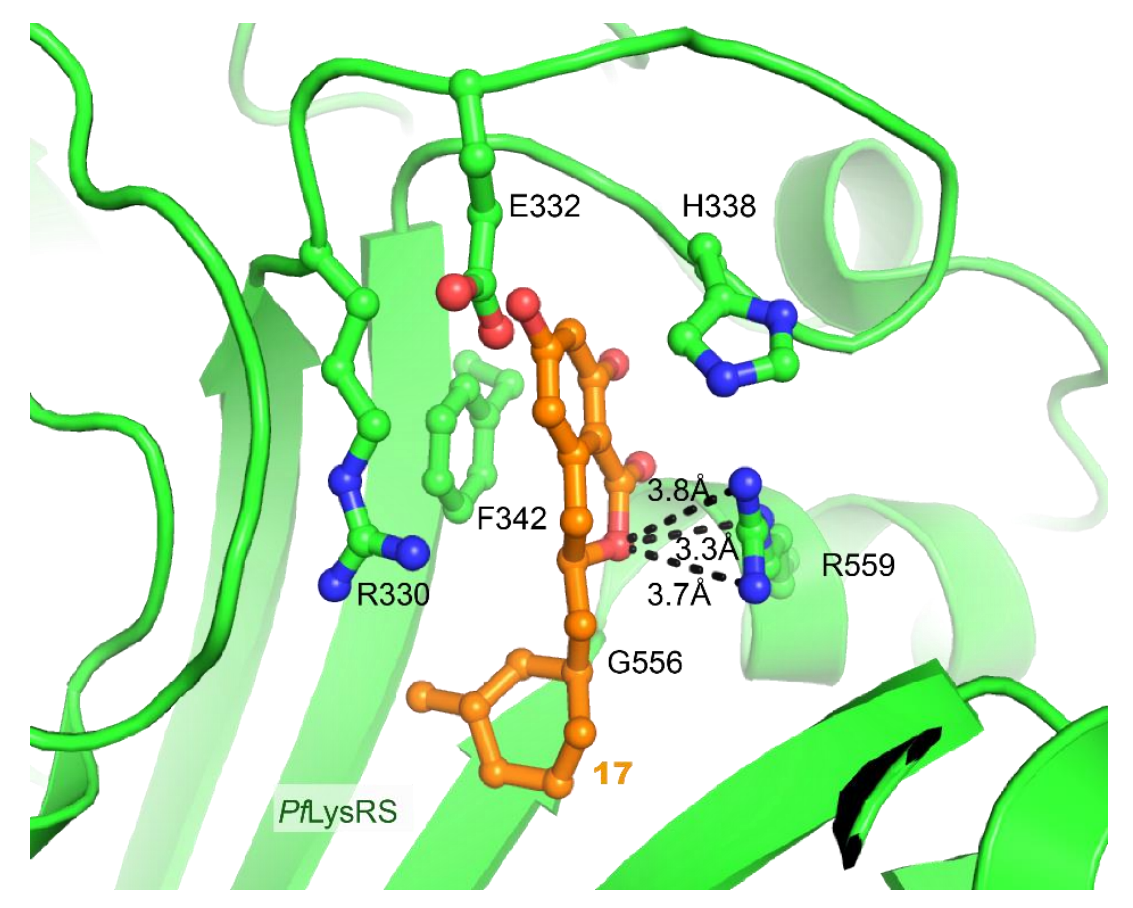

Figure S5. A zoom-in view of $P f$ LysRS-17 complex structure in the active center. The $P f$ LysRS is shown as a green cartoon. The compound $\mathbf{1 7}$ is shown as orange sticks. The interacting residues from the enzyme is shown as green sticks. The distances of the $\mathrm{O} 2$ atom toward the Arg559 residue are labeled. 

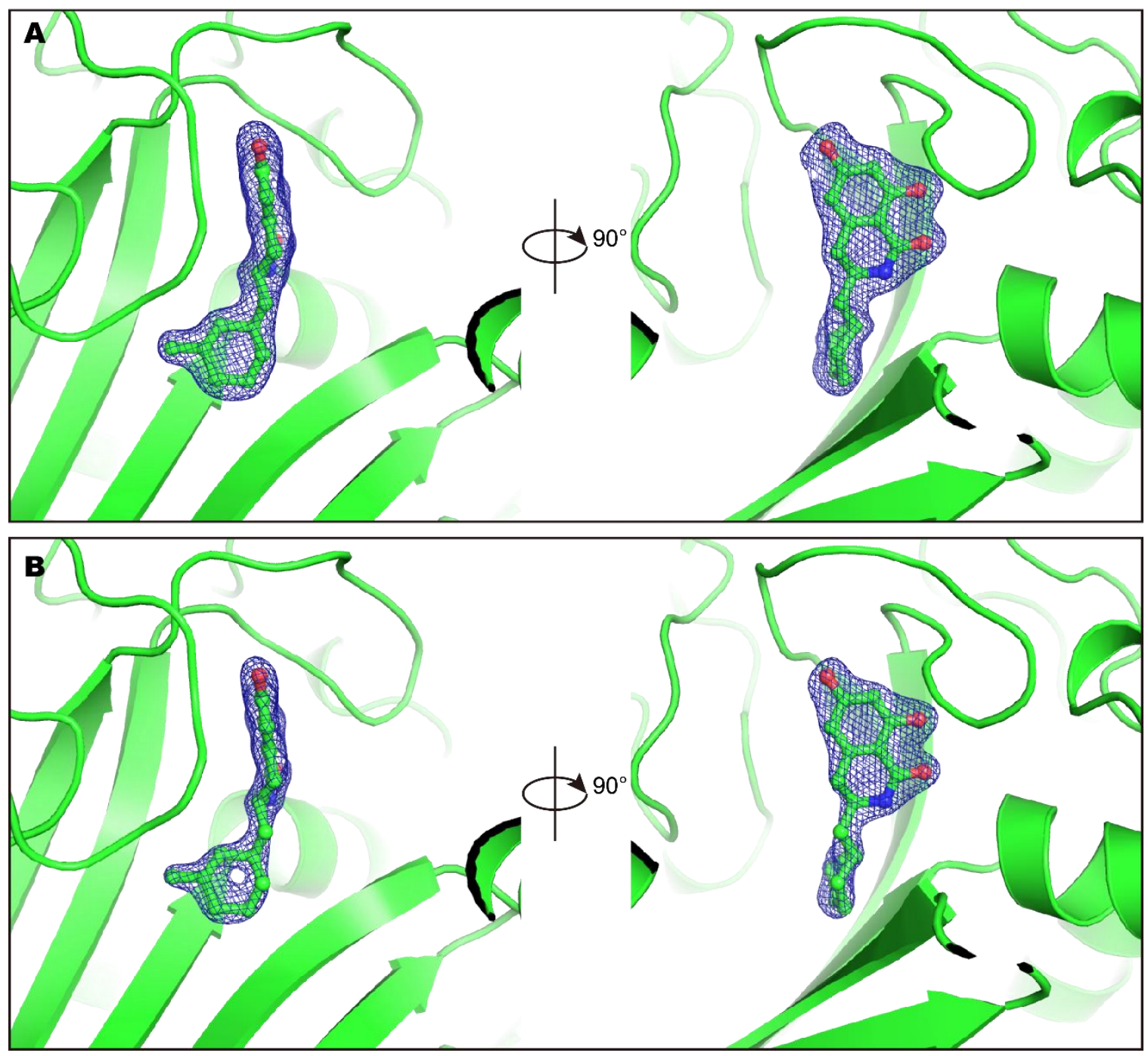

Figure S6. Electron density of compound 23 in the $P f$ LysRS-23 complex structure. (A) $2 \mathrm{Fo}-\mathrm{Fc}$ maps are contoured at $\sigma=1.0$ level. (B) $2 \mathrm{Fo}-\mathrm{Fc}$ maps are contoured at $\sigma=2.0$ level. 

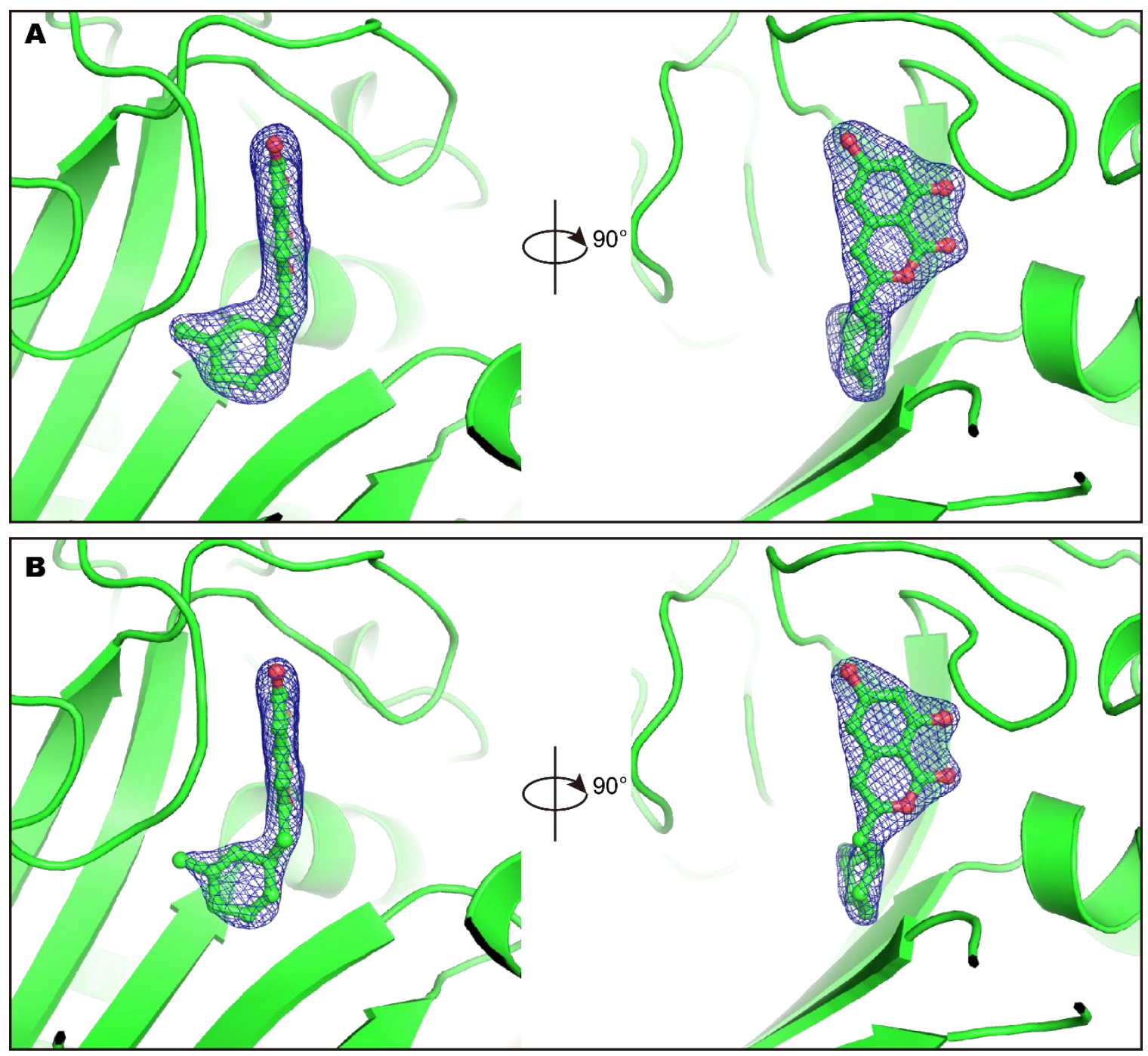

Figure S7. Electron density of compound 21 in the PfLysRS-21 complex structure. (A) 2Fo-Fc maps are contoured at $\sigma=1.0$ level. (B) $2 \mathrm{Fo}-\mathrm{Fc}$ maps are contoured at $\sigma=2.0$ level. 

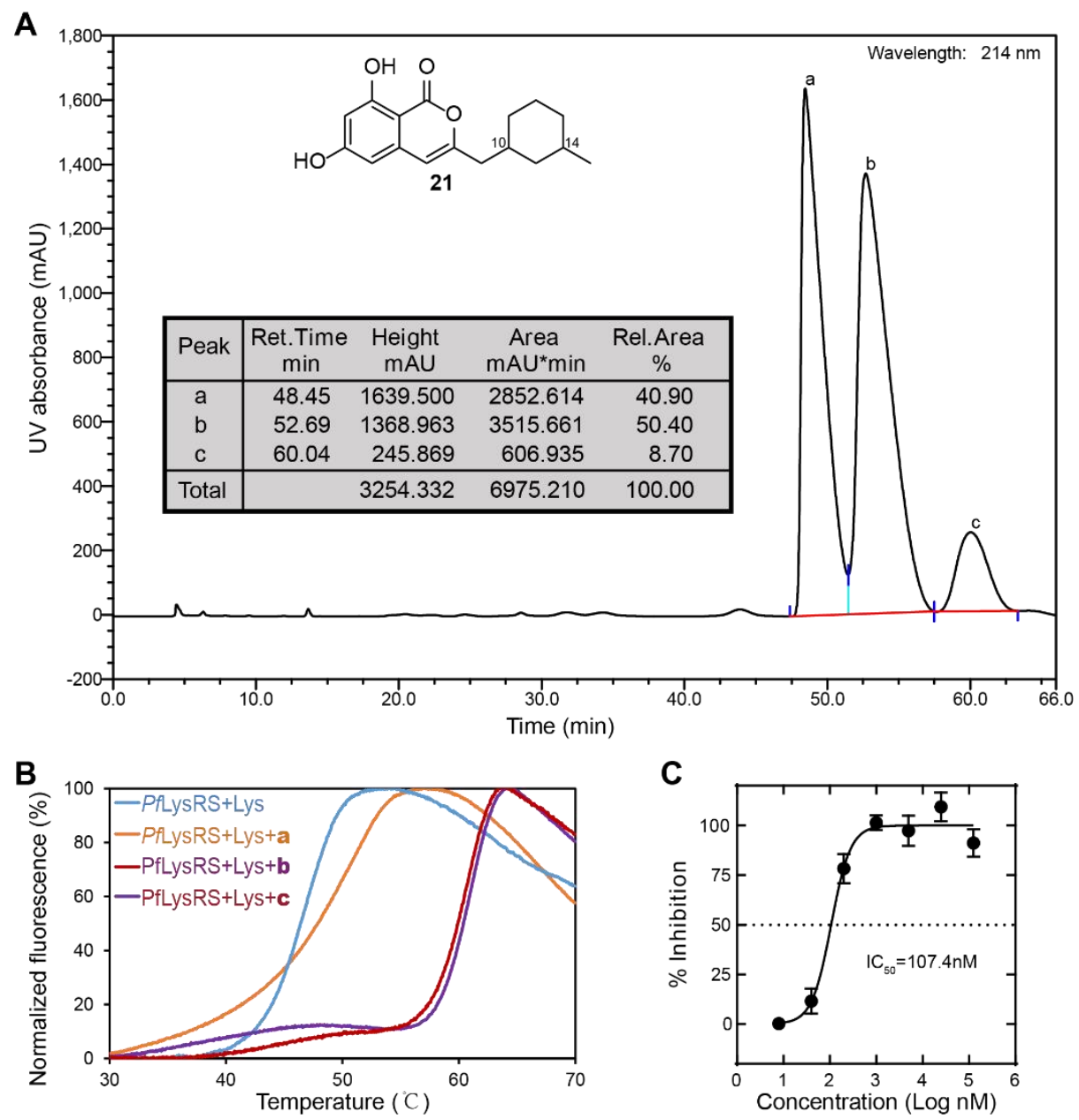

Figure S8. Stereoisomers analysis of compound 21. (A) Stereoisomers of compound 21 were separated by high performance liquid chromatography (HPLC). (B) Thermal melting profile of $P f$ LysRS in the presence of ligand L-lysine (Lys) and the three fractions in (A). Because only peaks $\mathbf{b}$ and $\mathbf{c}$ were highly active, the proportion of the active isomers in the total racemate was about 59\%. (C) Potency of peak cagainst PfLysRS is measured by the ATP hydrolysis assay. Error bars represent standard deviations (SD) of three repeats. 


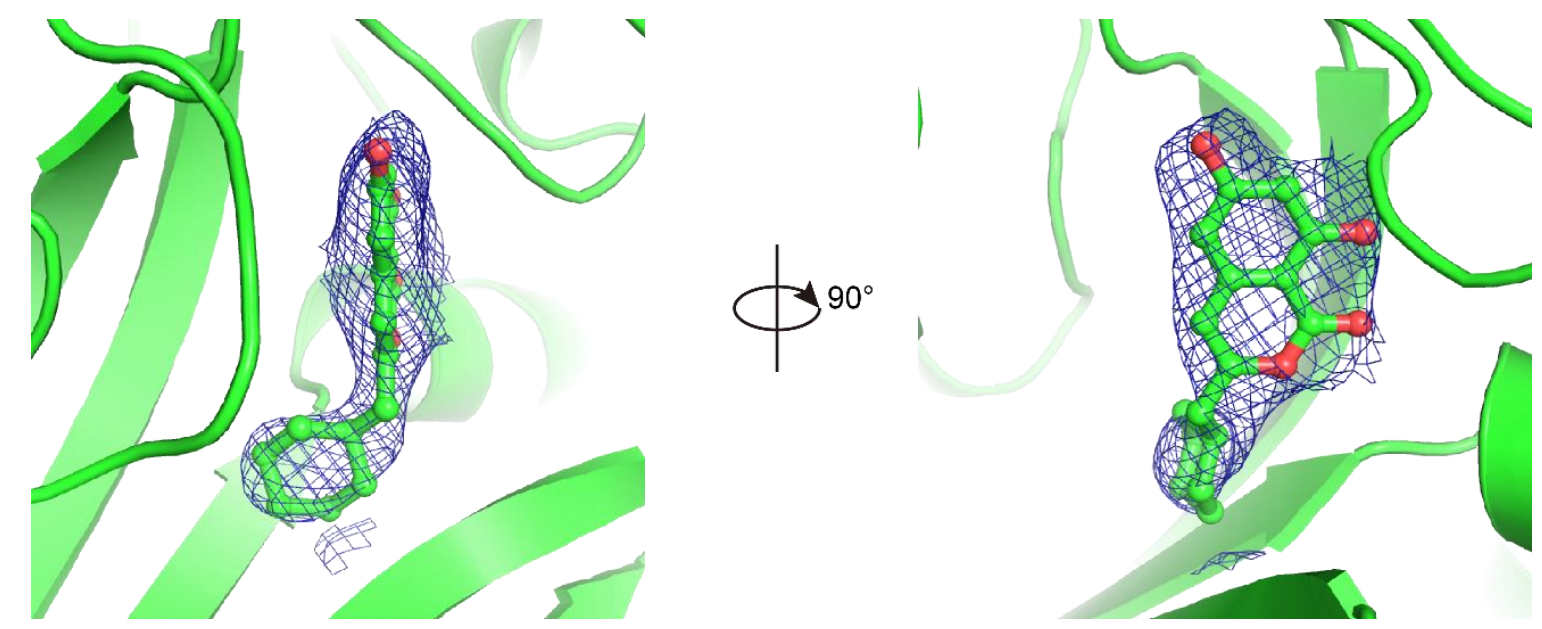

Figure S9. Electron density of compound 20 in the PfLysRS-20 complex structure. $2 \mathrm{Fo}-\mathrm{Fc}$ maps are contoured at $\sigma=1.0$ level. 


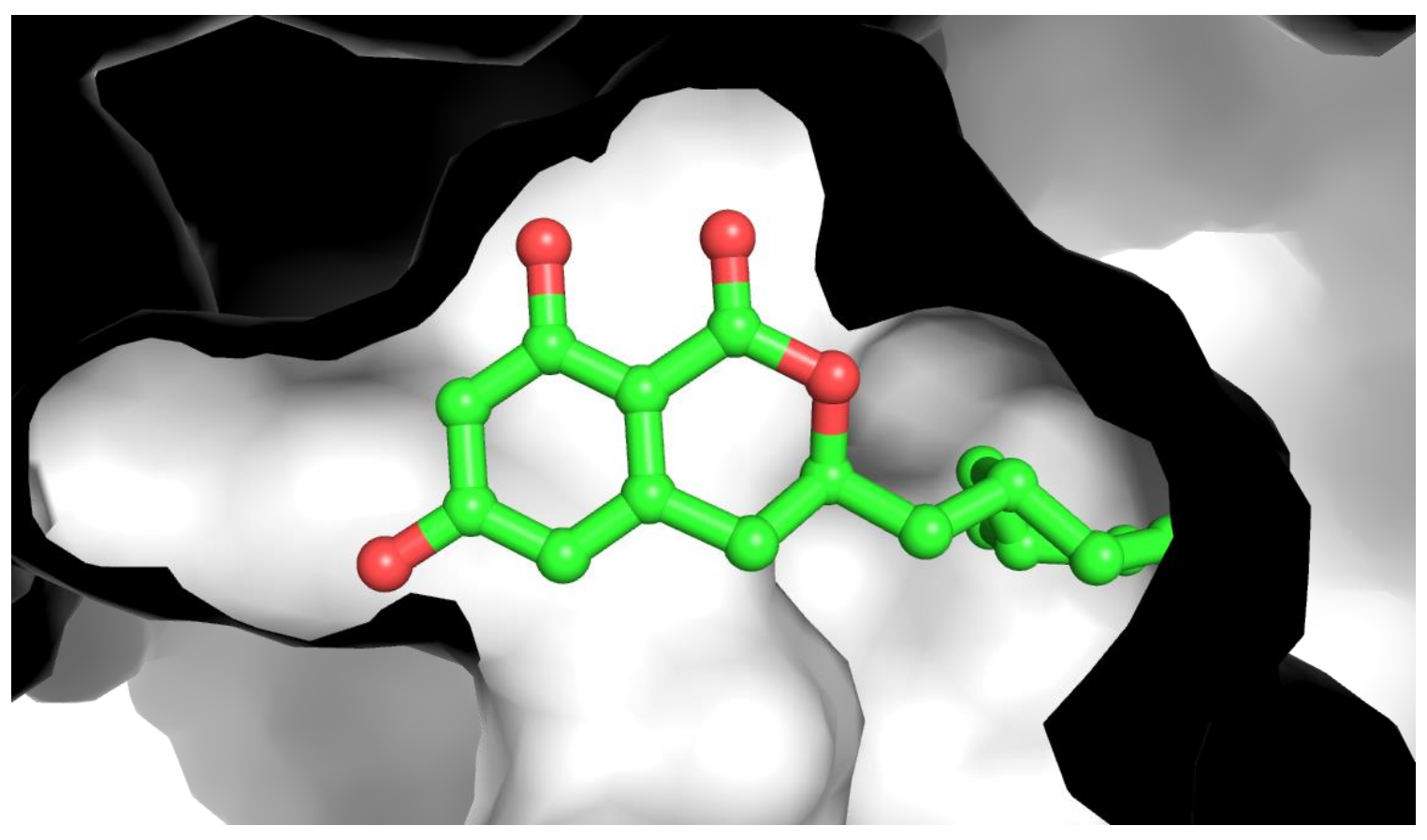

Figure S10. The ATP binding pocket of PfLysRS. The structure of $P f$ LysRS is shown as a white surface. The complexed compound $\mathbf{1 7}$ is shown as green sticks. 


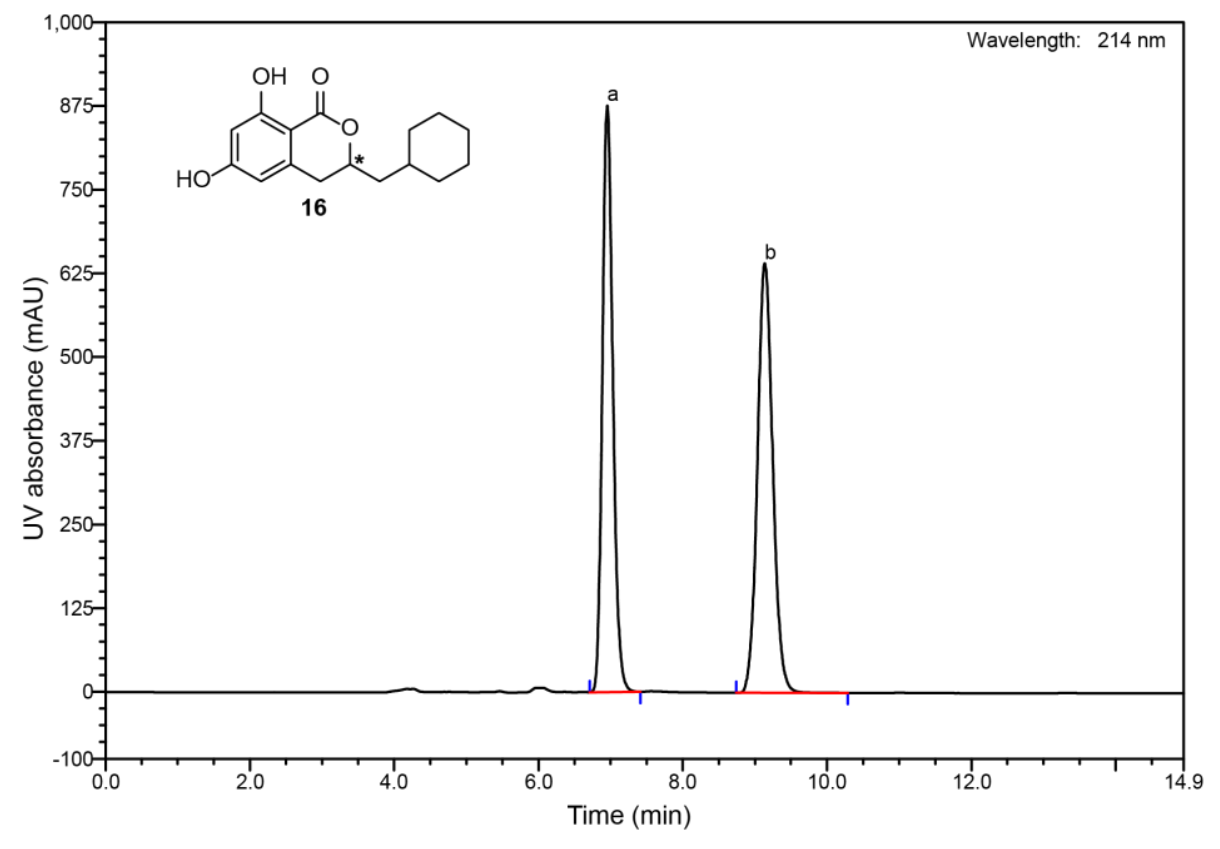

\begin{tabular}{|c|cccc|}
\hline Peak & $\begin{array}{c}\text { Ret.Time } \\
\text { min }\end{array}$ & $\begin{array}{c}\text { Height } \\
\text { mAU }\end{array}$ & $\begin{array}{c}\text { Area } \\
\text { mAU*min }\end{array}$ & $\begin{array}{c}\text { Rel.Area } \\
\%\end{array}$ \\
\hline a & 6.95 & 876.166 & 148.444 & 48.42 \\
b & 9.14 & 641.336 & 158.128 & 51.58 \\
\hline Total & & 1517.502 & 306.572 & 100.00 \\
\hline
\end{tabular}

Figure S11. Stereoisomers analysis of compound 16. Stereoisomers of compound 16 were separated by high performance liquid chromatography (HPLC) with about 1/1 ratio. Previous study on cladosporin (Das, P et al., 2018, J Med Chem 61, 5664) and crystal structures in this work indicated that only the $R$ configuration was active. 